\title{
PHYSICAL ACTIVITY, NOT DIET, SHOULD BE THE FOCUS OF MEASURES FOR THE PRIMARY PREVENTION OF CARDIOVASCULAR DISEASE
}

\author{
ALEXANDER L. MACNAIR \\ 20 Wimpole Street, London W1
}

CONTENTS

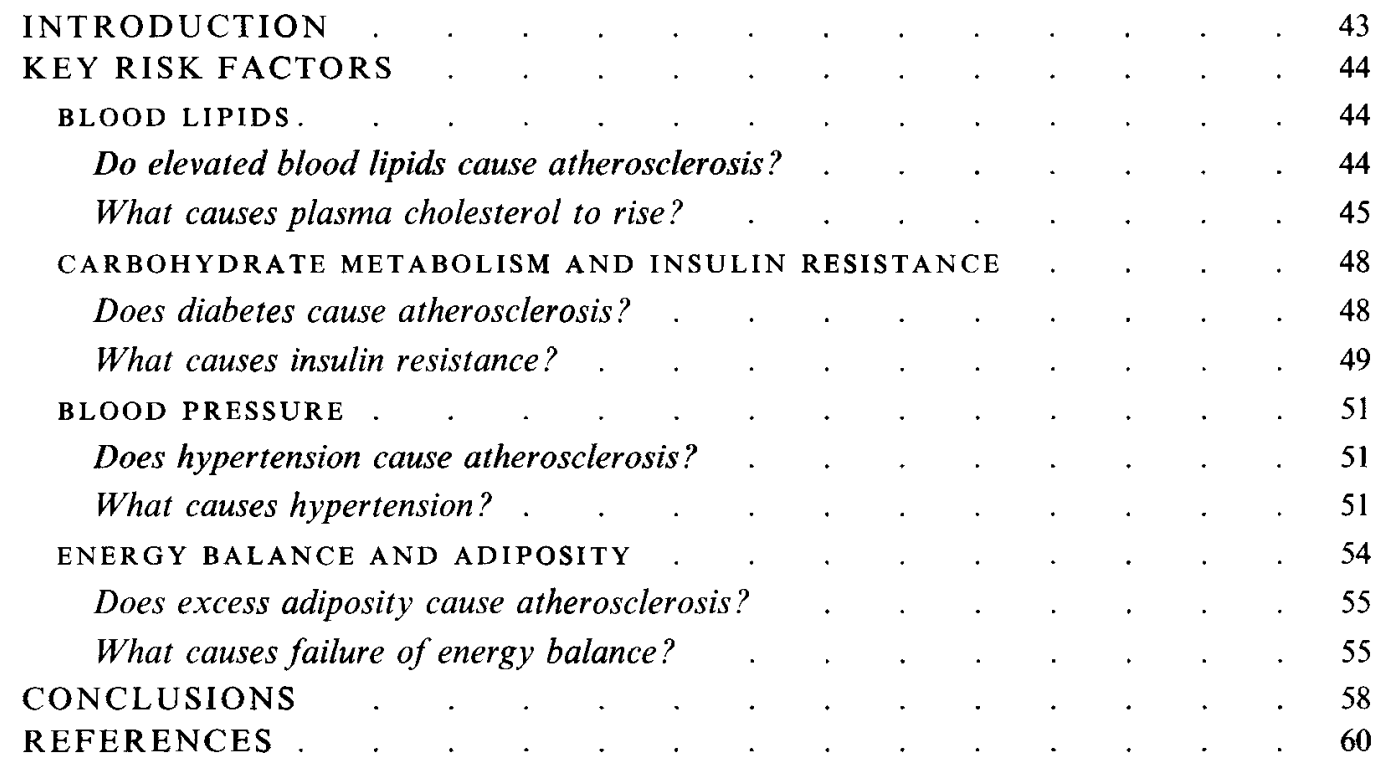

\section{INTRODUCTION}

Severe atherosclerosis is found at post mortem in the majority of cardiovascular deaths. Although this does not imply cause and effect, atherosclerosis is nevertheless an essential contributor to most of the disability and death associated with ischaemic heart disease (IHD) and its prevention must be a cornerstone of true primary prevention of IHD.

Progressive degeneration of the lining of the great vessels appears to begin in the first few years of life with the formation of fatty streaks beneath the endothelial lining, first of the aorta and later of the main arterial trunks. It continues to extend and to encroach upon the vascular lumen in susceptible subjects, often for half a century or more before occlusion of the vessel is sufficient finally to cause ischaemic injury to critical tissues downstream. Modest regression of lesions appears to be possible (Ornish et al. 1990) but atherosclerosis is very largely irreversible once fibrous plaque formation has become established (Davies, 1992). In consequence, primary prevention is increasingly being directed towards healthy subjects in their first two or three decades. Its objective is to encourage the making of relevant changes in behaviour that will continue for life on the basis that whatever initiates the atherosclerotic process may also sustain it. There is thus a need to identify the agents 
which operate first in the atherogenic process in the hope that their control may inhibit the emergence of the later stages.

The classic risk factors for atherosclerosis are chronic degenerative diseases in their own right and convincing evidence for any of them playing an individual causal role in atherogenesis has very largely eluded researchers in this complex area. The environmental causes of atherosclerosis itself, or of the dyslipidaemia, hypertension, disordered carbohydrate metabolism and obesity which may contribute to it, are by no means clearly understood, but in childhood at least there is little else to consider other than diet and the level of physical activity. Both are difficult to characterize in any single subject but there are easily measured surrogate physiological variables which show strong statistical associations with later cardiovascular morbidity and mortality. These are, in fact, the well established metabolic variables which relate to the uptake, transport, storage and utilization of fuel and oxygen to meet the energy requirements of the organism.

The objective of this paper is to consider each of the key risk factors for evidence of a causal role in atherosclerosis and at the same time to identify the cause or causes of the increase in the risk factor itself. It may be possible thus to determine not only the causes but also the order in which they become effective and to pinpoint the earliest triggering mechanism for atherosclerosis upon which true primary prevention might most fruitfully be focused.

\section{THE KEY RISK FACTORS}

\section{BLOOD LIPIDS}

\section{Do elevated blood lipids cause atherosclerosis?}

How good is the evidence that the classic changes in lipid and lipoprotein concentrations associated with a high risk of IHD (elevated plasma total cholesterol, low density lipoprotein (LDL) and triacylglycerol (TG) together with diminished high density lipoprotein (HDL)), actually cause atherosclerosis? Steinberg (1983) argues that elevated plasma concentrations of LDL are alone sufficient to cause atherosclerosis. Patients with homozygous familial hypercholesterolaemia, who have high plasma concentrations of LDL and no other identified risk factors, may suffer from severe atherosclerosis and die from IHD at a very early age. Familial hypercholesterolaemia is, however, an inherited metabolic disease characterized by LDL receptor dysfunction and plasma cholesterol concentrations which may approach six times normal, leaving deposits of cholesterol in connective tissue throughout the body. It does not necessarily represent a model for the dyslipidaemia associated with idiopathic atherosclerosis in which LDL elevation is much more modest and lowered HDL an important if not essential concomitant. The absence of normal LDL receptor function in these unfortunate individuals results in the prolonged sojourn in the circulation of large numbers of LDL particles. Henriksen et al. (1981) demonstrated that LDL may be converted by endothelial cells to a modified form involving the peroxidation of lipids in the LDL particle. Modified LDL is both cytotoxic (Hessler et al. 1979) and unrecognizable by the LDL receptor. Nevertheless, it is avidly taken up by the scavenger receptors of a high capacity alternative pathway deployed by monocyte derived macrophages, by Kupffer's cells in the liver and by vascular endothelial cells (Goldstein et al. 1979). It is not known how free radical attack is mounted by the endothelial cells (although they are the main source of very highly reactive nitric oxide) but lipid peroxidation may be an explanation for the atherogenicity of familial severe and prolonged hypercholesterolaemia. Much of the LDL in the circulation may be abnormal, quite apart from the possibility that the endothelial cells themselves, with absent or 
abnormal LDL receptors, may differ functionally; neither should it be overlooked that the vasculature as a whole is exposed to the abnormal lipid levels and yet most vessels remain free of atherosclerosis.

LDL is a normal plasma constituent, and where there is normal receptor function it is not easy to understand how a small elevation in LDL can contribute significantly to atherogenesis. Not only are antioxidants widely available both in LDL particles and in the plasma, but HDL also inhibits the cytotoxicity of oxidized LDL (Hessler et al. 1979). It may be that the duration of exposure of LDL particles to the endothelium, as much as their absolute concentration, permits greater oxidative modification and enhances their atherogenic potential. In normal healthy subjects, plasma half-lives of the lower density lipoprotein particles vary according to their fractional catabolic rates, which are as much dependent on the demand, principally by skeletal and cardiac muscle, for fatty acids for energy production, as upon the rate of recycling of LDL receptors and uptake by the liver.

Most widely accepted as the fundamental basis of atherosclerosis is the endothelial injury hypothesis (Ross, 1986). Ross and Glomset's original hypothesis (Ross \& Glomset, 1976) was predicated upon hypercholesterolaemic injury to the endothelium. Their primate model (Faggiotto et al. 1984; Faggiotto \& Ross, 1984) exhibited grossly exaggerated levels of plasma cholesterol (six times normal) achieved by giving a high fat, high cholesterol diet to animals with a genetic predisposition (the animals were selected for experiment by their hypercholesterolaemic response to the diet). Furthermore, they were taken from a breeding colony and confined in single cages for the duration of the study. The animals were weighed monthly but changes in their body weights were not reported. Kramsch et al. (1981), employing a similar protocol, studied a closely related strain of macaque. As well as atherogenic diet and control groups, they added a third which was given the high fat, high cholesterol diet and animals in this group were also exercised on a treadmill, three times per week, eventually for an hour. Monkeys in the exercise group lost about $12 \%$ body weight $(0.6 \mathrm{~kg}$ from a starting weight of about $5 \mathrm{~kg})$ while the sedentary groups gained about as much. Most monkeys on the lipid-rich diet, whether exercising or not showed a 6-fold increase in total cholesterol. However, the exercise group alone showed an increase in HDL cholesterol with less of a rise in LDL, VLDL and plasma TG than their inactive fellows. Examination by electrocardiogram, by coronary angiography and at post mortem, showed striking protection from atherosclerosis in the exercising animals as compared with their sedentary counterparts. These observations reinforce the notion that hypercholesterolaemia per se may not be atherogenic, and it is worth considering that Ross's model, with confinement of the animals throughout the study, depends more on physical inactivity for the development of atherosclerosis than on the elevated blood lipids.

\section{What causes plasma cholesterol to rise?}

In classic human atherosclerosis, the more modest derangement in blood lipid levels includes a disturbed ratio of high to low density lipoproteins and often an excess of TG. Since human diets in affluent societies provide more or less equivalent proportions of energy from fat and carbohydrate, while muscles employ a fuel mix which approximates to the ratio in the diet (Flatt, 1987), it is possible that the atherosclerosis seen in man with its origins in childhood, where clustering of metabolic risk factors is common (Webber $e t$ al. 1979; Berenson et al. 1989), includes inactivity in its pathogenesis and that hypercholesterolaemia is but one facet of a metabolic derangement which involves both fat and carbohydrate metabolism.

Compared with all other mammals, man is hypercholesterolaemic from soon after birth (Brown \& Goldstein, 1986). At birth, the human blood concentration of LDL is similar to that of other mammals in which, by contrast with man, there is little change throughout 
life. This initial concentration is adequate to provide for the physiological functions of LDL in relation to LDL receptor populations and their affinities (Reichl et al. 1978). In the human, however, immediately after birth in all races studied, the cholesterol concentration rises rapidly, doubling in the first six month of life and redoubling by two to three years when it approaches that of the young adult (Berenson et al. 1979; Sporik et al. 1991). The fasting TG concentration also rises rapidly, increasing by some two-and-a-half-fold by six months (Berenson et al. 1979).

This early rise in blood lipids may have its roots in the evolution of modern man. Brain development, particularly growth of the forebrain, is very recent and has required a considerable increase in the capacity of the cranium. Although gestation may have shortened from perhaps 50 to 40 weeks, the female pelvis has had to become significantly modified to permit the passage of the larger head during parturition, as is shown in the fossil record (Pilbeam, 1984). A consequence of these changes for the human infant is that maturation of the central nervous system is far from complete at birth when the brain is still only a quarter of its adult size. By the end of the first year, the greater part of the postnatal increase in brain weight has taken place and it is about $75 \%$ of its adult size. Most of the increase is the result of nerve axon myelination. Myelin is largely lipid of which about $40 \%$ is cholesterol. The exceptional cholesterol requirement of the neonatal central nervous system may account for the high blood cholesterol concentration during the first few months of life.

Body fat accumulation also is very rapid in the newborn human; at 1-2 months, when blood lipids are rising fast, fat deposition is about $14 \mathrm{~g} / \mathrm{d}$. At $5-6$ months the rate falls to $1 \mathrm{~g} / \mathrm{d}$ but by then body fat has doubled from $13 \%$ of body weight at birth to $25 \%$ (Fomon et al. 1982). The absence of myelin renders the long motor tracts within the central nervous system inoperative until myelination is complete. As a result, the human infant's voluntary musculature is, except for simple spinal reflexes, largely uncoordinated at birth. The less coordinated early activities of the child are at most lightly loaded and, although apparently vigorous, actually require a low level of energy expenditure. In contrast, purposive locomotion in bipeds lifts the total body weight at each step and demands a high energy expenditure. Thus the human infant, unlike its lower primate cousins, is relatively sedentary with low energy expenditure for up to a year. A possible explanation for the high concentration of TG in the circulation in the first few months is the obligatory low level of energy expenditure. Taken together, these consequences of the evolution of a large brain and its late maturation may account for the exceptionally high concentration of blood fats and the unexpected but universal finding in humans of fatty streaks in the aortae of virtually all two to three year olds (Strong \& McGill, 1969).

Whether or not there is an evolutionary explanation for the high blood levels of LDL cholesterol and TG in all young children, by the time they reach adult life the blood lipid pattern differs significantly between those from rural economies and those living in urban communities. An additional environmental explanation is clearly required, and it is traditional, when discussing the causes of elevation of plasma cholesterol in adults, to cite Kinsell et al. (1952), Ahrens et al. (1954), Keys et al. (1957) and Hegsted et al. (1965), for they and others showed, under metabolic ward conditions, that the proportion or the saturation of fatty acids in the diet has an effect upon the concentration of cholesterol in the blood. Experiments in free living subjects, however, cast doubt on the relevance of these early findings, showing a capacity in most individuals to compensate for dietary change by altering absorption, synthesis or elimination of cholesterol (McNamara et al. 1987). Furthermore, cross-sectional studies in large numbers of free living subjects have consistently failed to show an important relationship between any dietary component and plasma cholesterol (Morris et al. 1963; Kahn et al. 1969; Gordon, 1970; Nichols et al. 1976; 
Frank et al. 1978). Agreement about which fatty acids in the diet have effects upon the blood cholesterol level has still to be reached (Sundram et al. 1994), although Dietschy et al. (1993) have proposed that individual dietary fatty acids have specifically defined effects on LDL receptor activity which directly determines the plasma concentration of LDL.

Considered functionally, both fats and sugars in the blood are fuels en route ultimately to the muscles for oxidation. Exercise training increases the capacity of skeletal muscle tissue to take up oxygen and to release energy from these metabolic fuels. It also increases the ratio of fat to carbohydrate oxidized by muscle (Romijn et al. 1993). A small but meticulous study, comparing trained locomotor muscle groups against the contralateral untrained muscle groups in individuals exercising one leg over an 8 week period, measured the lipids in the blood entering and leaving trained and untrained muscles, both at rest and during exercise (Kiens \& Lithell, 1989). At rest in the trained leg, there was a markedly higher arteriovenous difference in VLDL TG. There was also a difference, albeit smaller, in the production of LDL at rest. There was a higher production of HDL during exercise in the trained leg.

There are more conventional studies showing the effects of exercise on plasma lipids (Wood et al. 1983; Rauramaa et al. 1984) but they tend to be confounded by changes in body composition. However, Weintraub et al. (1989), in a carefully controlled study, kept weight constant during a treadmill training programme and altered the total energy but not the proportions of the diet to match the increased expenditure. Although weight remained constant, fitness increased as measured by maximal oxygen uptake. Fasting TG concentrations fell significantly and there was a tendency for VLDL and LDL to fall while HDL rose but the latter changes were not significant in this small group of 6 subjects. Exercise significantly increased lipoprotein lipase activity while postprandial total lipoprotein levels were reduced by $32 \%$.

The textbook presentation of plasma lipid transport (Brown \& Goldstein, 1991) is as a system for both fatty acids and cholesterol. However, examination of the structure of an LDL particle (Brown \& Goldstein, 1984) shows that the cholesterol is functionally involved both in the formation with fatty acids of hydrophobic esters and in the hydrophilic limiting membrane in which bipolar molecules of free cholesterol and phospholipid share in the make-up of the detergent monolayer. The exogenous pathway for lipid transport is manifestly a TG transport system while the endogenous pathway (of which LDL is a part) is remarkably parallel. Chylomicrons are synthesized in the intestine from TG of dietary origin while VLDL are synthesized in the liver from endogenous TG; both incorporate apoproteins E, CII and B. Apo CII activates lipoprotein lipase in adipose and muscle tissue capillaries, releasing TG for uptake by these tissues. Chylomicron remnants bearing apo $\mathrm{E}$ and apo B complete the exogenous pathway and are rapidly taken out of circulation by the liver. In the endogenous pathway VLDL particles, although smaller than chylomicrons, have a very similar structure and fate. Apo CII sees to the release of TG in adipose and muscle tissue and the VLDL remnant, now renamed intermediate density lipoprotein, is also taken up by the liver, albeit much more slowly than chylomicron remnants. A large proportion continues to circulate in the blood and progressively loses its remaining TG and apoproteins (except B) to become LDL. Thus although it is generally stated that LDL is a transporter of cholesterol, it is in effect a remnant of endogenous TG transport. This question of the function of lipoprotein particles is of key importance since the accumulation of LDL in the circulation may be at least as much the consequence of disparities in supply and demand for TG as failure of down-regulated or absent LDL receptors to clear it. Chylomicrons and their remnants are cleared from the plasma with a half-life of 4-5 min; the half-life of VLDL particles is 1-3 h. LDL particles, on the other hand, have a prolonged stay in the circulation with a fractional catabolic rate of about $45 \%$ of the plasma pool in 
$24 \mathrm{~h}$. In a study of LDL balance in the whole organism in several species, Dietschy and his colleagues (1993) concluded that, contrary to earlier assumptions, LDL does not function in a major way to deliver cholesterol from the liver to extrahepatic organs, and the amount of cholesterol synthesis taking place in extrahepatic tissues is 3-5 times greater than the amount being delivered to these organs by LDL. Thus far from being a cholesterol transport particle, LDL may simply be the ultimate degradation product of the TG transport system. Some cholesterol is of course utilized outside the liver in steroid hormone and vitamin $\mathbf{D}$ synthesis but the absolute amounts are small.

The studies of Weintraub et al. (1989) and Kiens \& Lithell (1989) indicate that changes in blood cholesterol concentrations reflect the turnover of TG and lipoprotein lipase activity which are in this context an expression both of the level of muscle training and of the level of physical activity. Lipoprotein lipase, although activated by apo CII, is feedback inhibited by local accumulation of the fatty acid products of hydrolysis of TG as muscle uptake becomes satiated (Quinn et al. 1982), a point quickly reached in muscle tissue continuously at rest and in particular if it is also untrained. Such inhibition of hydrolysis of lipoprotein TG will not only raise the concentration of lower density lipoprotein particles in the circulation but will also prolong the duration of their stay, increasing their exposure to reactive oxygen species released from the endothelium and elsewhere. If cholesterol is present in lipoprotein particles as a functional element rather than as a passenger, then cholesterol concentrations and the associated cardiovascular risk may depend on fatty acid turnover, which is a function of the level of physical activity and the state of training of the skeletal muscle. The fact that some plasma cholesterol is associated with increased risk and some with risk reduction further supports the view that cholesterol is itself not causally associated with IHD.

There are as many studies pointing to exercise and physical activity as a key determinant of the plasma lipoprotein profile as there are metabolic ward studies of dietary fats in this role. A meta-analysis involving 95 such studies (Tran \& Weltman, 1985) showed that there are, indeed, significant relationships between physical activity and changes in blood lipids and lipoproteins. Decreases in total cholesterol, LDL, TG and the total cholesterol:HDL$\mathrm{C}$ ratio were correlated significantly with exercise training especially when accompanied by weight loss, but the most consistent results were seen in studies in which there was no weight change. Longer exercise times were also significantly associated with greater changes in lipid and lipoprotein levels. In children also, a low level of physical activity is associated with a high total plasma cholesterol concentration (Wong et al. 1992).

In the light of these data it seems possible that the cause of the classic changes in concentration and metabolism of plasma lipoprotein particles associated with increased risk of atherosclerotic cardiovascular disease may be the failure to maintain some personal or individual minimum threshold level of training that is probably genetically determined.

\section{CARBOHYDRATE METABOLISM AND INSULIN RESISTANCE}

\section{Does diabetes cause atherosclerosis?}

If, as seems increasingly possible, the fundamental origin of atherosclerosis is in a failure of metabolic fuel regulation, it is logical having considered the lipids to review the role of carbohydrate metabolism and in particular non-insulin dependent diabetes (NIDDM) in this context since in affluent societies, where a choice of foods is freely available, energy is derived about equally from dietary fats and carbohydrates. In childhood and adolescence, when atherosclerosis is believed to have its origin, NIDDM is not common. It is a classic disorder of middle age in which poor control of blood glucose 
concentration is a consequence both of insulin resistance and of relative failure of pancreatic production of insulin (DeFronzo, 1988) but the origins of NIDDM may, nevertheless, be in childhood. There are few studies examining glucose tolerance or insulin resistance in children but Freedman et al. (1987), as part of their monitoring of the classic risk factors in children in the Bogalusa Heart Study, showed that a hyperinsulinaemic response one hour after an oral glucose load is associated strongly with the amount of centrally located adipose tissue. In adults there is an established relationship between central obesity, glucose intolerance, hypertriacylglycerolaemia and hypertension. Kaplan (1989) described this cluster of risk factors as 'The Deadly Quartet' and considered that central obesity was the cause of the disturbances in lipid and carbohydrate metabolism and a contributor to the hypertension. Reaven (1988), however, described as 'syndrome X' a group of metabolic disturbances comprising glucose intolerance, hyperinsulinaemia, hypertriacylglycerolaemia with a rise in VLDL and a decline in HDL together with hypertension. Citing very largely his own work, he argued that the metabolic changes and the hypertension could all be seen as secondary to insulin resistance. The original description of syndrome $\mathrm{X}$ did not include obesity, and it is interesting in this context that patients with insulinoma may manifest marked visceral fat deposition, apparently under the influence of the hyperinsulinaemia (Inadera et al. 1993). It is possible that hyperinsulinaemia leads to deposition of visceral fat rather than the more usually accepted reverse sequence. Indeed, it may be that visceral fat is the more potent risk factor than peripheral fat precisely because, unlike the gluteofemoral adiposity in women which has an oestrogenic basis, it is a consequence of insulin resistance and elevated insulin levels.

Over 25 years ago Stout $(1968,1991)$ and Vallance-Owen (Stout \& Vallance-Owen, 1969) argued that glucose and insulin play a major role in the genesis of atherosclerosis. In the light of current evidence, Jarrett (1988) considered the question 'Is insulin atherogenic?' $\mathrm{He}$ concluded that the case was not proven and, in his view, the hypothesis requires more experimental and observational evidence before it can be supported. In a later review, Jarrett (1992) also provided a well argued case against elevated insulin levels as a cause of hypertension in syndrome $\mathrm{X}$.

There is little evidence either that hyperglycaemia, rather than hyperinsulinaemia, is atherogenic. Persistently raised blood glucose has adverse effects on the microvasculature, especially in the retina (Kohner, 1993) and renal glomerulus (Lorenzi, 1992), but there is no good evidence that the vessels classically involved in atherosclerotic disease are damaged by hyperglycaemia. Thus although syndrome $\mathrm{X}$ and Kaplan's quartet comprise the main risk factors for IHD and both include impaired glucose tolerance, the epidemiological evidence linking NIDDM to IHD is not sufficient for a causal relationship to be seriously considered. Nevertheless, it is clear that the combined disorders of lipid and carbohydrate metabolism, central obesity and hypertension are together linked with atherosclerosis, and an understanding of the way these disorders arise may help in elucidating the origins of disease in the blood vessels.

\section{What causes insulin resistance?}

Insulin resistance or reduced insulin-mediated glucose uptake is defined as a subnormal response to a given concentration of insulin and measured usually by the euglycaemic, hyperinsulinaemic glucose clamp developed by DeFronzo et al. (1979). Although insulin has integrated actions on carbohydrate, protein and lipid metabolism, it exerts a dominant effect on glucose homeostasis and the term 'insulin resistance' typically refers only to the latter (Moller \& Flier, 1991). Reaven (1988) makes it clear, however, that insulin resistance includes a reduced ability to regulate the plasma free fatty acid concentration. Indeed he shows that failure to regulate non-esterified fatty acids is in part responsible for fasting 
hyperglycaemia in NIDDM since elevated blood levels of non-esterified fatty acids stimulate hepatic gluconeogenesis.

Shulman et al. (1990) obtained ${ }^{13} \mathrm{C}$ nuclear magnetic resonance spectra of human muscle glycogen in vivo. By this means they were able to show that muscle glycogen synthesis is the principal non-oxidative pathway for glucose disposal. It was about $60 \%$ lower in their insulin resistant subjects than in normals and total body glucose uptake was likewise depressed. Shulman and his colleagues concluded that impaired glycogen synthesis in skeletal muscle appears to be the dominant intracellular metabolic basis of insulin resistance. Björntorp (1987) analysed the sequence of events leading to NIDDM and observed that the earliest evident metabolic anomaly in the development of NIDDM is increased insulin resistance in skeletal muscle. Young et al. (1988), using radiolabelled glucose, determined that, in insulin resistant subjects without diabetes, glycogen accumulation in muscle during infusions of glucose and insulin is diminished in comparison with normal subjects. Eriksson et al. (1989) compared NIDDM subjects with their first degree relatives and a group of normal controls. They found a high prevalence of insulin resistance, even in relatives with normal oral glucose tolerance. In perfused rat hindquarters, prolonged exposure of skeletal muscle to high plasma levels of insulin and glucose causes muscle glycogen to increase and then plateau while glycogen synthesis, rapid at first, attenuates to zero after about $5 \mathrm{~h}$ (Richter et al. 1988a). The mechanism of this acute insulin resistance involves both membrane transport of glucose and glycogen synthesis, apparently in response to high intracellular glucose and glycogen concentrations. In vitro studies with cultured rat adipocytes provide evidence that a high level of insulin alone may induce insulin resistance (Garvey et al. 1986), while Richter et al. (1988b) have shown that high plasma levels of glucose alone lead to marked inhibition of insulin action on muscle glucose transport. In effect, any check on the flux through the system taking glucose from the blood, polymerizing it to glycogen and oxidizing the product to release energy may cause a local excess of substrate, product or regulator and down-regulation of insulin receptors as a result. Man has little capability to dispose of excess levels of glucose by conversion to fatty acids in adipose tissue (Björntorp \& Sjöström, 1978), something that happens freely in the rat. Unlike liver glycogen, that in muscle is unavailable for release back into the circulation as glucose and once synthesized in muscle it can only be mobilized by utilization for energy release within the cell. When muscle glycogen stores are replete, there is feedback inhibition of further glycogen synthesis. If blood glucose is elevated following a meal, insulin resistance occurs when the rising blood insulin level fails to move glucose out of the circulation. Once the relatively small glycogen storage capacity of the liver is surpassed, any excess glucose from the diet is shunted through into the peripheral circulation where, in spite of a raised insulin concentration, it produces prolonged hyperglycaemia before the tissues take it up finally by mass action.

Insulin resistance can be seen to be the normal physiological response to relative carbohydrate overfeeding. It stems from failure to utilize available stores of glycogen in muscular work, the consequence either of a low level of energy expenditure in physical activity or of dietary intake of carbohydrate in excess of that needed to make good normal carbohydrate turnover. These observations suggest that insulin resistance is the consequence of inactivity coupled with a relative excess of dietary energy in the form of carbohydrate while the obesity, that may be seen in association with syndrome $X$ and is a part of the deadly quartet, may simply be the consequence of an excess of dietary energy intake in the form of fat. The usual location of this obesity in the abdominal area suggests an association with insulin resistance and hyperinsulinaemia. Although there is a dearth of good studies in children, there is no reason to suppose that insulin resistance does not occur in childhood or that its fundamental cause is other than a low level of physical activity. 
The enforced idleness of the human infant may contribute to the high level of fat deposition in the first year. One may speculate that if that inactivity is voluntarily prolonged it may adversely affect a critical period of musculoskeletal development which perhaps culminates in the growth spurt of puberty. Barker (1992) has proposed that the pathogenesis of cardiovascular disease is programmed during the period of rapid growth in early life; however, his data are retrospective and confined to anthropometric measures routinely recorded during the first year. They are not accompanied by metabolic risk factor data recorded concurrently. Young athletes undergoing vigorous training are taller and slimmer than sedentary controls (Ekblom, 1971). Structural and metabolic differences in trained as opposed to untrained muscle in young adults are profound (Ingjer \& Brodal, 1978; Kiens \& Lithell, 1989) but we do not know whether the level of activity or training plays an important role in the early development of skeletal muscle. There are no data from studies comparing either carbohydrate metabolism or muscular development in active as opposed to inactive children. Such studies would be uniquely valuable in elucidating the relevance of early nutrition and exercise in achieving optimum muscular development in childhood.

\section{BLOOD PRESSURE}

\section{Does hypertension cause atherosclerosis?}

In the pantheon of risk factors for IHD, blood pressure vies with plasma cholesterol for first place (Martin et al. 1986). The key question is whether there is evidence that it is a cause of atherosclerosis and therefore of fundamental importance for prevention. In fact, this is one area in the complex question of the aetiology of atherosclerosis where the evidence is rather clearcut. There is no doubt that atherosclerosis is confined to blood vessels where the pressure is highest. Typically it starts in the aorta, especially where branches and flow dividers cause turbulence (Texon, 1980). Later it involves the main branches at the points where they leave the aorta. It affects, in particular, the coronary arteries in which flow ceases during ventricular systole, giving an exaggerated and possibly more damaging pulsatile component to the effects of pressure. Atherosclerosis does not appear to involve lower pressure vessels on the arterial side of the circulation or any of the veins except when a vein is used as a bypass graft and becomes subjected to arterial pressure.

Schwartz \& Benditt (1977) carried out careful observational studies of the effects of blood pressure on the endothelial cells of the aorta in the rat and showed that the earliest sign of endothelial injury in hypertension is a ten-fold increase in cell replication. Texon (1986) showed in man that the hydraulic forces acting at bends and branches tend to lift the endothelial layer from its basement membrane. The loss of laminar flow induces local negative pressure which causes cell junctions to gape or, by actually removing cells, exposes the underlying collagen. Platelets and white blood cells, including monocytes, flock to this lesion, described first as an inflammatory arteritis by Virchow (1858) and later by Ross \& Glomset (1976) as the beginning of atherosclerosis. There seems to be little doubt that even quite modest increases in blood pressure induce loss of normal function in endothelial cells and an increase in their normally slow turnover, which may be the first step in the long journey to the development of the classic atherosclerotic fibrous plaque and ultimately vascular occlusion.

\section{What causes hypertension?}

If the relationship between hypertension and atherosclerosis seems relatively clear, the cause of the hypertension itself remains in dispute. The second report of the Task Force on 
Blood Pressure Control in Children (1987) shows that in urban societies systolic blood pressure rises rapidly in the first six months of life. Both diastolic and systolic pressures increase steadily thereafter to reach adult levels at the end of the second decade when linear growth ceases. Blood pressure is closely tied to height (World Health Organization, 1985a).

The rise in blood pressure in childhood appears to be a universal phenomenon (Grobbee et al. 1990). Apart from an inherited predisposition, the cause of hypertension, particularly that which appears early, is not established. Ambard \& Beaujard (1904), in a treatise on the causes of arterial hypertension, described several cases in whom chloride retention was associated with elevated blood pressure and where salt deprivation led to a decline. Allen (1925) advocated salt restriction for the treatment of established hypertension, as did Kempner (1948). The point, however, is not whether salt deprivation will reduce elevated blood pressure so much as whether excess dietary salt is a cause of essential hypertension in the young. Here, the animal studies of Dahl et al. (1968) are compelling. Dahl and his colleagues demonstrated that rats given saline to drink may become hypertensive. By selective inbreeding they produced strains of rats which, given salt in their diet, became rapidly, permanently and severely hypertensive, or conversely were totally resistant to the hypertensive effects of salt. Dahl \& Love (1954) concluded that the same interaction between genetic predisposition and environmental conditions applies in man, and present understanding of the role of the kidney in maintaining blood volume and ionic concentration along with blood pressure control suggests that they were right. Both salt sensitive and salt resistant subjects can be found but the nature of the inherited defect remains unknown. In populations in whom salt intake is high, the proportion with hypertension is high in comparison with populations with a low salt intake (Dahl, 1972). Although in large groups of subjects there appears to be a dose response effect (Law et al. 1991), the individual blood pressure responses to dietary salt adjustment are extremely varied and heavily reinforced by multiple feed-back systems. Miller et al. (1987) undertook a twelve week intervention study in 82 individuals with normal blood pressure. Baseline sodium intake was $157 \mathrm{mmol} / \mathrm{d}$ and this was reduced to $68 \mathrm{mmol}$ during the restriction phase of the study. For the group as a whole, mean arterial pressure fell from $83 \mathrm{mmHg}$ to $81 \mathrm{~mm}$. Thus moderately severe sodium restriction produced a small reduction in mean arterial pressure for the group as a whole, as might be expected. However, when the individual responses are examined, they present a normal distribution about the mean and extend from a $15 \mathrm{~mm}$ reduction to a $17 \mathrm{~mm}$ increase in mean arterial pressure.

In reviews of the mechanisms involved in the genesis of chronic idiopathic hypertension, Guyton (1989) and de Wardener (1990) showed that it does not occur without abnormal function of the renal machinery for the maintenance of extracellular fluid volume and cation concentrations. In communities with a high salt intake, those with diminished renal capacity to excrete sodium and water respond to higher levels of salt intake by a greater rise in pressure than those with normal renal function. This phenomenon may explain why blood pressure rises with age in high salt consuming societies and may also be the basis of salt sensitivity, either genetic (e.g. a family trait towards a small renal tissue mass) or congenital such as inhibited growth and development in utero of genetically normal kidneys (Barker et al. 1990). Although there is no doubt that the blood volume and the basal blood pressure are affected physiologically and directly by habitual sodium intake, in those with normal renal function, the renin-angiotensin-aldosterone system is so effective that huge changes in salt intake are reflected by a millimetre or two change up or down in the blood pressure. More important, at a given salt intake the setpoint does not drift significantly, so that an increase in pressure with age in healthy normal subjects is to be expected only if their salt intake also rises. Thus, in subjects with normal renal function, a high salt intake is unlikely to be the cause of hypertension. 
It is well accepted that high blood pressure in childhood tends to track, frequently remaining elevated in adolescence (Voors et al. 1979) and on into adult life. Suggestions for the key determinant of blood pressure in childhood include familial predisposition (Van Hooft et al. 1988), increased relative weight (Stamler et al. 1978), lack of physical fitness (Fraser et al. 1983; Hofman et al. 1987), sodium and potassium intake (Geleijnse et al. 1990) and insulin resistance (Slater, 1991). Hypertension in childhood is associated with elevated lipids and arterial fatty streaks (Newman et al. 1986) as well as with obesity (Havlik et al. 1983) and hyperinsulinaemia (Freedman et al. 1987). Hofman et al. (1987) showed that children with declining physical fitness have above average rises in blood pressure, confirming the results of the earlier study by Fraser et al. (1983). Intervention to reduce weight in the overweight (Krotkiewski et al. 1979) or to restore fitness to the unfit (Somers et al. 1991) is, of course, desirable in its own right and can be an effective nonpharmacological means of reducing blood pressure in adolescents (Hagberg et al. 1984) or young adults (Jennings $e t$ al. 1986). There is at present little evidence from prospective long term childhood studies that avoiding fatness and maintaining fitness will prevent a rise in blood pressure above the normal for age and height, even if we knew what range of levels of adiposity and physical performance were normal or optimal. Furthermore, there is little real understanding at any age of the mechanisms by which elevation in one or more of the several risk factors for hypertension translates into an actual rise in blood pressure.

Dahl and his colleagues (Dahl et al. 1958) suggested that the hypertension of obesity is salt dependent and not simply a consequence of increased blood volume. However, others have questioned this thesis (Messerli, 1982; Frohlich et al. 1983), proposing increased cardiac output and blood volume as the principal determinants of blood pressure elevation in the obese. Dustan (1985) considered that various endocrine factors may be responsible for the relationship between obesity and hypertension. In her view none was a wholly satisfactory explanation but the data pointing to insulin in this role were the least unconvincing (Miller \& Bogdonoff, 1954; DeFronzo et al. 1975). DeFronzo and his colleagues studied the effects of an insulin infusion on sodium excretion during a euglycaemic clamp. There was a highly significant reduction in sodium excretion by the kidney as insulin levels rose, without changes in the filtered loads of sodium or glucose or in the glomerular filtration rate, renal blood flow or plasma aldosterone.

Modan and his associates examined a representative group of Jewish adults in a study of glucose intolerance, obesity and hypertension, the Israel GOH Study (Modan et al. 1987) and demonstrated that hyperinsulinaemia is independently associated with hypertension, glucose intolerance and a disturbed lipoprotein profile. Although in this cross-sectional study the causal chain of events could not be determined, Modan opined that obesity leads to hyperinsulinaemia which leads to the other conditions. Kaplan (1989), as we have noted, also proposed that obesity leads to glucose intolerance and hyperinsulinaemia which in turn precipitate hypertension and dyslipidaemia, but Reaven (1988), in a review of his own extensive studies on the relationship between insulin resistance and other diseases, noted that increases both in plasma catecholamines and in renal tubular reabsorption of sodium and water can be seen in response to hyperinsulinaemia and that either may lead to an increase in blood pressure. In support of the concept that insulin resistance leads on to hypertension, Beatty et al. (1993) showed that the young normotensive offspring of hypertensive parents were already insulin resistant by comparison with matched offspring of normotensive parents, even though they showed no signs of hypertension.

Julius et al. (1991) offered a hypothesis for the link between insulin resistance and hypertension. They proposed that the pathophysiological fault is in skeletal muscle and is 'vascular rarefaction', involving loss of vessels from the muscle capillary bed. Pressure induced restriction of the microcirculation limits nutritient flow and thereby impairs glucose 
uptake in skeletal muscle. However, they were not entirely clear which was cause and which effect. They suggested that hypertension causes microvascular damage with narrowing or loss of nutritive vessels (those which supply oxygen and fuel rather than non-nutritive or 'shunt' vessels) and this, by limiting blood flow through the muscle, led to reduced glucose uptake and insulin resistance. Baron et al. (1990 \& 1991) put the boot on the other foot with the measurement of glucose uptake and blood flow in the leg muscles in lean and obese men following an oral glucose load. Glucose uptake in muscle is part insulin receptor mediated and in part driven by mass action, the result of the difference in concentration of glucose in plasma and within the skeletal muscle cell. The obese subjects had impaired glucose tolerance. They also had hyperinsulinaemia both while fasting and after the glucose load. However, the arteriovenous differences in glucose concentration both while fasting and during disposal of the glucose load were the same in both lean and obese. Blood flow through the leg increased markedly in the lean subjects during the glucose load but was unchanged in the obese subjects. Thus the impaired glucose tolerance and apparent insulin resistance were partly, at least, the effects of failure of blood flow in skeletal muscle to increase rather than failure of transport of glucose into the myocyte. This mechanism, involving what seems at first sight to be a direct effect of insulin on blood vessel tone, may also be involved in the processes by which hyperinsulinaemia and hypertension appear to be connected.

Ingjer \& Brodal (1978) and Kiens \& Lithell (1989) showed how training increases the size of the muscle capillary bed and thus loss of fitness or 'detraining' may independently lead to reduced muscle capillary density, insulin resistance (Rosenthal et al. 1983) and an increase in blood pressure (Somers et al. 1991). It is not clear whether there is a direct or causal relationship, but if so it is logical to suppose that the low nutritient capillary density and reduced blood flow in untrained muscle is part of the cause both of the insulin resistance and of the enhanced resistance to flow which may be expressed as hypertension. Conversely, the increased capillary density in trained muscle may reduce the peripheral resistance to blood flow and contribute to the decline in resting blood pressure and heart rate associated with training.

We have in these observations a plausible hypothesis to explain the onset of a hypertension in children without hereditary or congenital predisposition. It appears likely that insufficient muscular activity to turn over glycogen stores with consequent insulin resistance and hyperinsulinaemia leads over time to a rise in resting blood pressure. Hyperinsulinaemia may in addition increase renal salt and water retention, while the increase in peripheral resistance that accompanies declining physical fitness may be associated with increases in both renin/angiotensin and sympathetic nervous system activity. Taken together with the relationship between physical activity or training and the utilization of lipids and carbohydrates by skeletal muscle, one can see how a level of activity and energy expenditure below some individual or personal threshold may lead to accumulation of metabolic fuels in blood and tissues along with insulin resistance and hypertension and their consequences.

\section{ENERGY BALANCE AND ADIPOSITY}

An excess of body fat is evidence of failure of energy balance. It is of limited value debating whether it is due to consuming too much energy or expending too little. Of considerable importance, however, are the answers to the questions, does excess adiposity cause atherosclerotic heart disease for which it is an established risk factor, and if so what causes the breakdown in energy balance which the majority of people manage exquisitely accurately without conscious effort for most of their lives? 


\section{Does excess adiposity cause atherosclerosis?}

Obesity is a relative latecomer to the risk factors for IHD. Hubert (1984), reviewing data recorded during 26 years' follow-up of the original Framingham cohort, proposed that the degree of adiposity is a significant and independent long term predictor of disease. The risk of cardiovascular disease is most pronounced in those younger than 50 who are most overweight and is independent of the influence of age, blood pressure, serum cholesterol, tobacco use, glucose intolerance and electrocardiographic evidence of left ventricular hypertrophy. No allowance was made in Hubert's analysis for the level of physical activity or energy expenditure. She reviewed also 10 major studies of the relationship between adiposity and IHD risk, concluding that their results, like her own, were consistent with the notion that adiposity plays a fundamental role in the causation of disease, but she made no attempt to speculate on the mechanism.

Lapidus et al. (1984), reviewing the data from their studies of adipose tissue distribution and the risk of IHD in both men and women, considered that the strength and independence of the association between excess abdominal fat and IHD spoke in favour of a causal relationship. They, too, offered no explanation other than a suggestion that a sex hormone imbalance may determine the site of the excess adipose tissue.

Dustan (1985) reviewed the association between hypertension and obesity. She pointed out that although there is a common view that obesity causes hypertension, it is quite possible that both are separate manifestations of some other underlying disorder. Physiological changes associated with excess adiposity include an increase in blood volume and cardiac output, hyperinsulinaemia, insulin resistance and impaired glucose tolerance, increased serum TG and cholesterol, increases both in cortisol secretion and in its metabolic clearance and also an increase in sympathetic nervous system activity. Weight reduction may restore most or all of these derangements to normal. However, weight change is itself the result of a fundamental shift in balance between energy intake and energy expenditure. Altering intake of certain nutrients or of energy, as well as changing energy expenditure by a variety of means, may have effects in their own right on any or all of these variables. Dustan was unable to explain the relationship between body weight and blood pressure but seemed to favour, with reservations, an endocrine factor (insulin or aldosterone) as its basis.

If we return to the concept that body fat is an indicator of energy imbalance, our analysis should consider energy balance per se. The evidence reviewed so far supports the notion that persistently reduced physical activity and energy expenditure may, if below a given individual's basic fitness threshold, lead to a variety of adverse effects on blood lipids, insulin resistance with its consequences and hypertension. The relationship between obesity and the other key factors may simply be that they are all secondary to physical inactivity. This suggestion, hinted at by Dustan (1985) in regard to hypertension, is made more plausible by Hubert's finding that excess adiposity is often the first risk factor to emerge and may be independent of all the others.

\section{What causes failure of energy balance?}

What information do we have pointing to the causes of energy balance failure and excess adiposity? Since both energy intake and energy expenditure (other than basal) are aspects of behaviour, the fundamental cause of their failure to balance, albeit considerably affected by genetic influences, is most probably also behavioural. The evidence from twin studies (Stunkard et al. 1986; Sørensen et al. 1989; Bouchard et al. 1990) underlines the influence of genetic factors but does not identify them. They are frequently assumed to be metabolic but there is no reason to suppose that they may not also involve behavioural characteristics 
such as an inclination to an active lifestyle or a preoccupation with food. Ravussin et al. (1988) showed that a low rate of energy expenditure at rest tends to cluster in families and to predict an increased risk of weight gain in adults. Roberts et al. (1988) demonstrated that a low level of energy expenditure is an important factor in excessive weight gain in the first year of life and is, at least in part, an inherited characteristic. It is clear that a low resting energy expenditure is significantly determined by genetic predisposition. What is not clear is why some people avoid physical activity and others find it an essential requirement for their wellbeing.

There has been a wide variety of animal models of obesity but the simplicity of Ingle's (1949) obese rat model is appealing. He confined normal laboratory rats in small individual cages and fed $a d l i b$. a palatable, largely carbohydrate diet. On this regimen the animals achieved $200 \%$ of ideal weight. With either a palatable diet or restriction of activity alone, weight gain was minimal. In a more complex study in rats, using graded treadmill exercise, Mayer et al. (1954) showed that energy expenditure and intake are closely correlated at all levels above a threshold of minimal activity. Like Ingle, he found that inactive animals given a palatable diet lose their precise control of food intake and gain weight. In a later study in workers in a jute mill near Calcutta, Mayer and his colleagues (1956) plotted the energy costs of individuals working at the mill, and commuting on foot or by bicycle, against their food energy intake. Those who were the most active consumed more but were no heavier than those whose efforts were more modest. Here too, energy intake and expenditure correlated at all levels of activity above a 'sedentary threshold'. Below this level, inactive employees (clerks and stall holders) tended to eat more than they required to replace the energy they expended, and were overweight.

On the basis of these and other studies in rats and in man, Mayer (1953) proposed a glucostatic mechanism for regulating food intake. Both protein and fat reserves can sustain the energy needs of the body for months without food intake whereas carbohydrate stores, mostly in the form of muscle glycogen, provide less than a day's energy requirement. Mayer postulated that appetite regulation depended on the extent to which glycogen stores are depleted by the day-to-day muscular work, since food seeking behaviour in humans (and in rats) is initiated several times each day. He showed that hunger was associated with the arteriovenous difference in glucose concentration, a reflection of insulin mediated glucose uptake. Mayer did not consider insulin resistance in this context, but he did attempt to elucidate the apparent anomaly of the hunger experienced by untreated diabetics which had initially been a stumbling block to acceptance of a theory of appetite regulation by blood sugar. Subjects with high blood sugar but decreased utilization (because of insulin deficiency) report feelings of hunger, presumably because insulin dependent glucose uptake into the 'glucostat' sensor celis is low and is perceived as a low availability of blood sugar. One may speculate that in obese subjects the same situation applies and hunger may be experienced because of insulin resistance and reduced glucose uptake in spite of the elevated blood glucose levels that are frequently seen in overweight subjects.

Mayer proposed also that fat and amino acid utilization were in some way regulated by this system, but it has become apparent that fat needs some other form of regulation while the small contribution to total energy intake from protein may be largely unregulated except insofar as it provides a substrate for gluconeogenesis. Flatt (1987) argues that at stable body weight the dietary ratio of fat to carbohydrate must approximate the ratio metabolized to provide energy. In consequence, changes in body composition may occur when there is a mismatch between the ratio of fuels oxidized and the nutrient proportions of the diet. Flatt's model, like Mayer's, requires that food intake is geared primarily to the maintenance of adequate glycogen stores. However, a mechanism by which fat stores are controlled is required not only because fat may provide as much of the daily energy intake 
as does carbohydrate, but more importantly because for most people body weight is precisely controlled over long periods and change in weight, when it occurs, is predominantly in the adipose tissue mass.

In summary, in a normal healthy subject food intake is probably controlled physiologically by the ebb and flow of glycogen, the bulk of which is stored in and used by skeletal muscle with a smaller reserve in the liver from which the fasting blood sugar level is maintained. Total expended energy is derived in approximately the proportions that fats and carbohydrates contribute energy to the diet (after inclusion of the contribution from protein). Carbohydrate utilization has priority and fat becomes the buffer between the daily intake and expenditure of energy. Fat stored in the portal adipose tissue mass, rich in insulin receptors (Björntorp, 1990), is especially easily mobilized if there is an energy shortfall, and this tissue is also a convenient short term storage site for fatty acids temporarily in excess of requirement. A normally nourished subject maintains fat stores in the region of $20 \%$ of body weight (about $15 \%$ for men, $25 \%$ for women) and daily fluctuations are thus a fraction of $1 \%$ of total body fat. However, in subjects who persistently consume an excess of energy it is stored as fat and body weight increases progressively. Should a normal $70 \mathrm{~kg}$ man gain $30 \mathrm{~kg}$, his fat store will show a $400 \%$ increase while body weight goes up by only $40 \%$. Such a proportional increase in adipose tissue causes an elevation in the blood level of non-esterified fatty acids. Even though in an overweight subject the rate of non-esterified fatty acid release per unit of adipose tissue mass is inhibited by an elevated blood insulin, the large overall increase in the fat mass still produces an absolute elevation in blood non-esterified fatty acids (Flatt, 1987). A feature of the glucose fatty acid cycle (Randle et al. 1963) is the restriction imposed on glucose metabolism in muscle by the enhanced release of fatty acids from adipose tissue. Thus there is a clearcut mechanism, which may require a change in body composition, by which an excessive intake of dietary fat will in the long term increase the ratio of fat to carbohydrate metabolized to release energy. A steady state will be reached in which body weight and composition will be maintained until the habitual dietary ratios change or the basic level of activity is altered.

Both the ratio of metabolic fuels metabolized and the total expenditure of energy depend also on the habitual level of activity of the subject. The level of physical training determines the demand for glucose and triacylglycerols and influences the lipoprotein levels in the plasma (Kiens \& Lithell, 1989). Endurance training increases the size and number of mitochondria as well as the bulk of the contractile fibres within the cell. It also increases the proportion of type I (slow twitch) fibres which are dependent on the oxidation of fatty acids for most of their energy requirement. At the same time, capillary density in skeletal muscle increases markedly with training (Ingjer \& Brodal, 1978). Lipoprotein lipase activity also increases in parallel since this enzyme is deployed on the luminal surface of capillaries in both muscle and adipose tissue. Physical training increases insulin sensitivity by increasing the number of receptors on skeletal muscle cells (Soman et al. 1979). According to the provisions of the glucose-fatty acid cycle, the enhanced uptake of glucose inhibits the release of non-esterified fatty acids. Thus training significantly modifies the ratio of metabolic fuels oxidized as well as increasing both basal and total energy flux through the organism.

We can begin to see that Mayer's 'sedentary threshold' may hold the key to avoidance of energy imbalance and an increase in adiposity. Subjects who fail to maintain a minimum level of training lose muscle contractile tissue along with some of the mitochondria which provide ATP from glucose and fatty acids. In addition, nutritive capillaries in muscle disappear along with their inherent lipoprotein lipase activity. Insulin receptors become less responsive and fewer in number. As a result of failure to utilize stored glycogen by muscular 
work, the normal glucostatic regulation system no longer provides hunger and satiety cues to eat and to stop eating. The ready availability of a highly palatable diet in a culture in which food has important social and hedonic functions may mean that appetite becomes controlled by intellectual triggers which lack both the sensor driven feedback and the precision of normal glucose-insulin regulated appetite. In particular, satiety signals may be absent or overridden and adipose tissue may thus begin to accumulate. In addition, insulin resistance is likely to emerge and encourage a 'false hunger'. Research in this area is very limited and yet it seems that the proximate cause of excess adiposity is a sedentary lifestyle in a congenitally susceptible subject with access $a d$ lib. to a palatable diet. Prevention of weight gain very probably requires a level of physical activity or training above an individual's 'sedentary threshold' which may be determined by genetic predisposition.

\section{CONCLUSIONS}

The primary prevention of most cardiovascular disease requires that the initial cause of atherosclerosis be identified in order that chronic degenerative changes in the blood vessels can be prevented from developing. Several elements in the vascular occlusive process, once established, are not reversible in any important sense and may be self-sustaining if not actually self-amplifying.

There is insufficient evidence to confirm or deny a causal role for disorders of fat and carbohydrate metabolism or, indeed, for obesity in the initiation of the chronic degenerative disease process in atherosclerosis. However, the predilection of atherosclerotic lesions for sites in blood vessels under the greatest pressure, in those with intermittent flow and at points of greatest hydrodynamic stress, singles out hypertension as the principal aetiological agent in the initiation and maintenance of atherosclerosis.

Primary hypertension appears to have a multiplicity of causes but the time course in both human and experimental hypertension suggests that whatever initiates the early pressure elevation, it is structural change, medial hypertrophy and vascular amplifier effects (Korner, 1994) which contribute increasingly and very largely irreversibly to the persistent elevation in blood pressure. The changes in the vessel wall may be reinforced by the simultaneous development of left ventricular hypertrophy. Thus we are left with the objective of pinpointing the cause of the initial elevation in blood pressure before structural changes in both heart and blood vessels supervene.

The key elements of both the deadly quartet and syndrome $\mathrm{X}$ can be seen to follow from habitual inactivity. Hypertension is central to both and appears to follow muscle wasting. On the one hand, reduced capillary density in large muscle masses and diminished vasodilator responsiveness in the absence of demand for oxygen increase peripheral vascular resistance. On the other, insulin resistance reduces muscle blood flow, adding to peripheral resistance, while hyperinsulinaemia encourages sodium retention and may stimulate smooth muscle proliferation in the resistance vessels (Stout, 1991).

Glucose intolerance stems from the relatively tiny capacity of the carbohydrate stores, while the pathway for conversion of excess glucose to fatty acids is rudimentary in nonobese humans. If muscle glycogen stores are not regularly depleted by physical activity, prolonged hyperglycaemia and insulin resistance are inevitable consequences.

Hypertriacylglycerolaemia is a direct result of diminished lipoprotein lipase activity which follows reduced capillary density in wasting skeletal muscle. It is also the result of visceral obesity which readily provides the liver with an increased supply of fatty acids as substrate for VLDL synthesis and secretion. Kaplans' quartet includes upper body obesity which may be a consequence of positive energy balance combined with hyperinsulinaemia. Reaven's syndrome ' $\mathrm{X}$ ' identifies decreased $H D L$-cholesterol as a 
related element. Studies of endurance training show that either the associated weight loss or increased fitness or both raise HDL (Wood et al. 1988), while monitoring muscle metabolism during physical training shows that HDL is produced in trained muscle tissue in parallel with the rise in lipoprotein lipase activity consequent upon the increase in capillary density (Kiens \& Lithell, 1989). These interconnected consequences of loss of training and muscle wasting (with or without energy imbalance) may explain why risk factors tend to cluster in individuals in the second and third decades when the high energy requirements for growth decline and ultimately cease. Social and economic pressures in affluent societies frequently operate at this time with the change from full time education to economic independence with often marriage, children and home making to limit opportunities for physical exercise sufficient to maintain a minimum level of fitness.

Quite separately, pathological inactivity, because of a reduced blood flow reserve, renders the heart more vulnerable to ischaemia and yet requires it to work harder, even at rest, against an increased peripheral resistance. The resulting hypertrophy of the muscle of the left ventricle adds a further and important risk factor to those already existing as a consequence of inactivity. The high rate of mortality from coronary heart disease can be substantially reduced only if sudden unexpected coronary deaths, perhaps half of all coronary deaths, can be prevented (World Health Organization, 1985b). The data from Framingham show that a high resting pulse rate is strikingly associated with sudden cardiac death (Kannel \& Thomas, 1982). In contrast to the rapid resting pulse rate associated with hypertension and left ventricular hypertrophy (Staessen et al. 1991), a slow resting pulse rate is a dependable indicator of physical fitness (Blomqvist \& Saltin, 1983). This is consistent with physical fitness having a direct protective effect against sudden cardiac death.

Returning to consideration of diet as a preventive measure, it is difficult to see an effective preventive role for dietary modification. In wholly sedentary subjects, reduction in total dietary energy may help avoid obesity; maintaining energy balance inhibits the emergence of insulin resistance and hyperinsulinaemia as well as obesity. Reduction in dietary fats and carbohydrates may help to minimize the accumulation of excess lipid and glucose in the blood and tissues. On the other hand levels of anti-oxidant vitamins in the diet may delay the modification of lipids in lipoproteins, rendering them less liable to scavenger pathway uptake by macrophages. Salt restriction if sufficiently profound may assist some sedentary and salt sensitive subjects to reduce their blood pressure. However, there is no evidence that any dietary manipulation will affect total peripheral resistance, resting heart rate, sympathetic outflow or any other cardiodynamic function in a way that reduces the risk of sudden or premature cardiovascular death when the fundamental cause of the elevated risk is pathological inactivity.

Rose (1981), commenting on the population strategy and diet, showed that if 50 young men at average risk changed their diet to lower cholesterol by a mean $10 \%$ and continued that diet up to age 55 , one heart attack would be prevented while 49 individuals would have eaten 'differently' every day for $\mathbf{4 0}$ years and got little or nothing from it. Rose described this as the prevention paradox: "a measure that brings large benefits to the community offers little to each participating individual". There has never been an adequate intervention study in normal individuals to determine whether or not there would be large benefits for the community but studies in high risk groups show that the dietary lowering of cholesterol is difficult to achieve and benefits are usually small and often absent (Ramsay et al. 1991). On the other hand Fentem (1992) and others (Eichner, 1983; Paffenbarger et al. 1993) have reviewed the evidence for exercise in prevention of disease and shown that exercise enhances not only cardiovascular reserves but also metabolic and psychological function. Thus unlike dietary restriction from which the healthy normal young individual is unlikely 


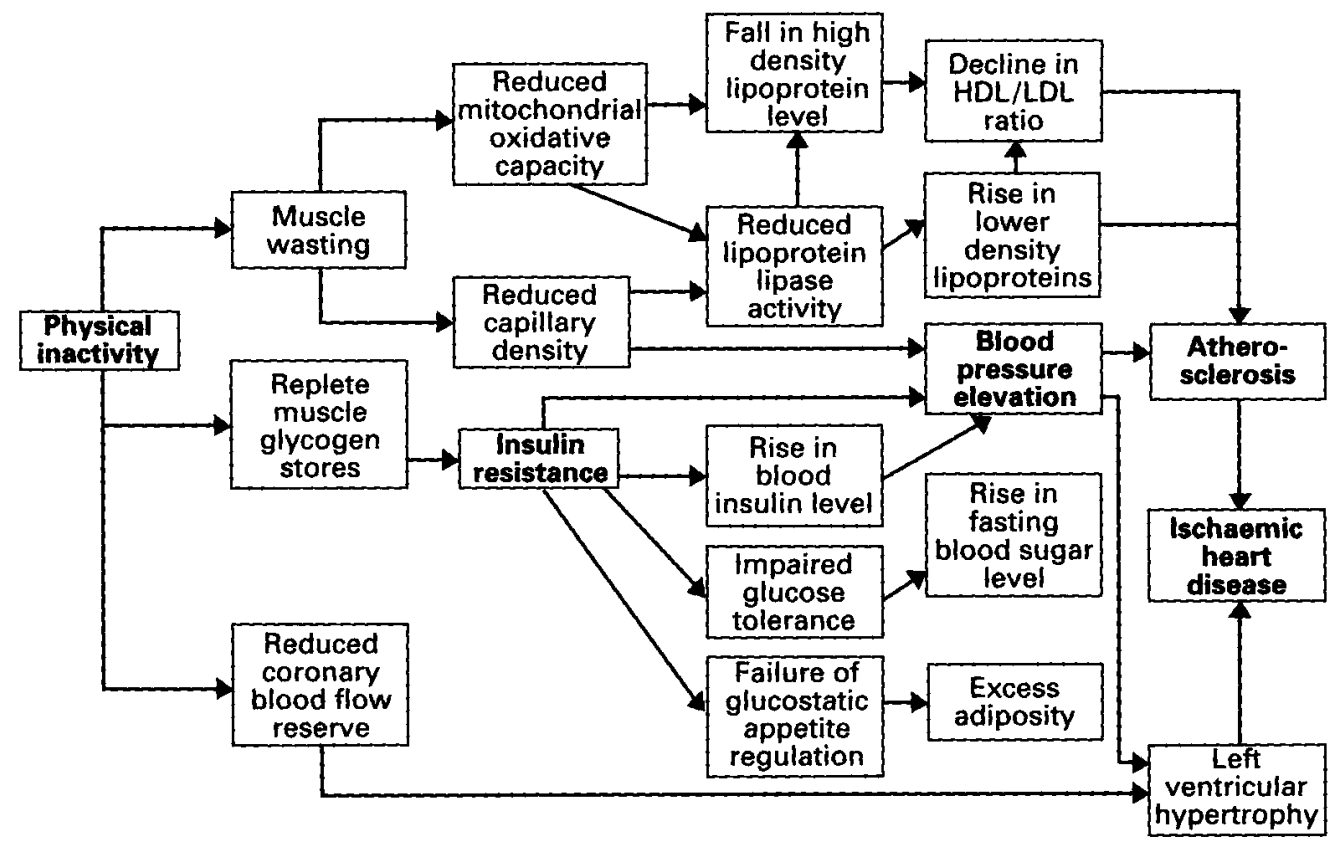

Fig. 1. Physical inactivity leads to underuse of both skeletal and ventricular muscle and failure to deplete glycogen stores in skeletal muscle. Both myocardium and skeletal muscle are left with reduced capacity to work while metabolic fuels tend to accumulate and skeletal myocytes become resistant to insulinstimulated glucose uptake. The combination of reduced capillary density, insulin resistance and hyperinsulinaemia drive up resting blood pressure. Endothelial damage induced by pressure initiates atherosclerotic vascular disease which is exacerbated by an excess of blood fats, while the increased peripheral resistance to flow causes blood pressure elevation and hypertrophy of the cardiac muscle with increased vulnerability to ischaemic damage and electrical instability. Note that excess adiposity, fasting hyperglycaemia and dyslipidaemia are associated with the risk of ischaemic heart disease but not necessarily causally in this schema. The direct pathogenetic pathway leads from physical inactivity through insulin resistance to hypertension which directly damages the endothelium, initiating and sustaining the atherogenic process.

to see any potential benefit or to get much pleasure, regular vigorous physical activity maintained into middle age may contribute importantly to physical and even psychological wellbeing as well as to the longevity of each active individual. Even here, there is little case for a population approach since human genetic diversity and differing cultural pressures require the informed individual to identify his own determinants of energy balance and needs for physical training from which to devise an acceptable personal strategy for their long term management. However, since excess adiposity is the principal marker for energy balance failure and also, possibly, of failure to surpass the 'sedentary threshold', the monitor for achievement and maintenance of the required level of activity or training may be as simple as regular use of the bathroom scales.

\section{REFERENCES}

Ahrens, E. H., Blankenhorn, D. H. \& Tsaltas, T. T. (1954). Effect on human serum lipids of substituting plant for animal fat in diet, Proceedings of the Society for Experimental Biology and Medicine 86, 872-878.

Allen, E. M. (1925). Treatment of Kidney Disease and Blood Pressure; (Part I). Newark, NJ : Newark Printing Company Inc.

Ambard, L. \& Beaujard, E. (1904). [Causes of arterial hypertension.] Archives Générales de Médecine S.H.1, $520-533$. 
Barker, D. J. P. (1992). Fetal and Infant Origins of Adult Disease. London: British Medical Journal.

Barker, D. J. P., Bull, A. R., Osmond, C. \& Simmonds, S. J. (1990). Fetal and placental size and risk of hypertension in adult life. British Medical Journal 301, 259-262.

Baron, A. D., Laakso, M., Brechtel, G. \& Edelman, S. V. (1991). Mechanism of insulin resistance in insulindependent diabetes mellitus: a major role for reduced skeletal muscle blood flow. Journal of Clinical Endocrinology and Metabolism 73, 637-643.

Baron, A. D., Laakso, M., Brechtel, G., Hoit, B., Watt, C. \& Edelman, S. V. (1990). Reduced postprandial skeletal muscle blood flow contributes to glucose intolerance in human obesity. Journal of Clinical Endocrinology and Metabolism 70, 1525-1533.

Beatty, O. L., Harper, R., Sheridan, B., Atkinson, A. B. \& Bell, P. M. (1993). Insulin resistance in offspring of hypertensive parents. British Medical Journal 307, 92-96.

Berenson, G. S., Blonde, C. V., Farris, R. P., Foster, T. A., Frank, G. C., Srinivasan, S. R., Voors, A. W. \& Webber, L. S. (1979). Cardiovascular disease risk factor variables during the first year of life. American Journal of Diseases of Childhood 133, 1049-1057.

Berenson, G. S., Srinivasan, S. R., Hunter, S. M., Nicklas, T. A., Freedman, D. S., Shear, C. L. \& Webber, L. S. (1989). Risk factors in early life as predictors of adult heart disease: the Bogalusa Heart Study. American Journal of the Medical Sciences 298, 141-151.

Björntorp, P. (1987). Adipose tissue distribution, plasma insulin, and cardiovascular disease. Diabète et Métabolisme 13, 381-385.

Björntorp, P. (1990). 'Portal' adipose tissue as a generator of risk factors for cardiovascular disease and diabetes. Arteriosclerosis 10, 493-496.

Björntorp, P. \& Sjöström, L. (1978). Carbohydrate storage in man: speculations and some quantitative considerations. Metabolism 27, Suppl. II, 1853-1865.

Blomqvist, C. G. \& Saltin, B. (1983). Cardiovascular adaptations to physical training. Annual Review of Physiology 45, 169-189.

Bouchard, C., Tremblay, A., Després, J.-P., Nadeau, A., Lupien, P. J., Thériault, G., Dussault, J., Moorjani, S., Pinault, S. \& Fournier, G. (1990). The response to long-term overfeeding in identical twins. New England Journal of Medicine 322, 1477-1482.

Brown, M. S. \& Goldstein, J. L. (1984). How LDL receptors influence cholesterol and atherosclerosis. Scientific American 251 (5), 58-66.

Brown, M. S. \& Goldstein, J. L. (1986). A receptor-mediated pathway for cholesterol homeostasis. Science 232 , 3447.

Brown, M. S. \& Goldstein, J. L. (1991). The hyperlipoproteinemias and other disorders of lipid metabolism. In Harrison's Principles of Internal Medicine, 12th edn, pp. 1814-1825 [J. D. Wilson, E. Braunwald, K.J. Isselbacher, R. G. Petersdorf, J. B. Martin, A. S. Fauci \& R. K. Root, editors]. New York: McGraw-Hill.

Dahl, L. K. (1972). Salt and hypertension. American Journal of Clinical Nutrition 25, 232-244.

Dahl, L. K. \& Love, R. A. (1954). Evidence for a relationship between sodium chloride intake and human essential hypertension. Archives of Internal Medicine 94, 525-531.

Dahl, L. K., Knudsen, K. D., Heine, M. A. \& Leitl, G. J. (1968). Effects of chronic excess salt ingestion: modification of experimental hypertension in the rat by variations in the diet. Circulation Research 22, 11-18.

Dahl, L. K., Silver, L. \& Christie, R. (1958). Role of salt in the fall of blood pressure accompanying reduction of obesity. New England Journal of Medicine 258, 1186-1192.

Davies, M. (1992). Atherosclerosis - can regression be achieved? Cardiology in Practice 10, 4-5.

DeFronzo, R. A. (1988). The triumvirate: $\beta$-cell, muscle, liver: a collusion responsible for NIDDM. Diabetes 37 , 667-687.

DeFronzo, R. A., Cooke, C. R., Andres, R., Faloona, G. R. \& Davis, P. J. (1975). The effect of insulin on renal handling of sodium, potassium, calcium, and phosphate in man. Journal of Clinical Investigation 55, 845-855.

DeFronzo, R. A., Tobin, J. D. \& Andres, R. (1979). Glucose clamp technique: a method for quantifying insulin secretion and resistance. American Journal of Physiology 237, E214-E223.

De Wardener, H. E. (1990). The primary role of the kidney and salt intake in the aetiology of essential hypertension. Clinical Science 79, 193-200, 289-297.

Dietschy, J. M., Turley, S. D. \& Spady, D. K. (1993). Role of liver in the maintenance of cholesterol and low density lipoprotein homeostasis in different animal species, including humans-review. Journal of Lipid Research 34, 1637-1659.

Dustan, H. P. (1985). Obesity and hypertension. Annals of Internal Medicine 103, 1047-1049.

Eichner, E. R. (1983). Exercise and heart disease: epidemiology of the 'exercise hypothesis'. American Journal of Medicine 75, 1008-1023.

Ekblom, B. (1971). Physical training in normal boys in adolescence. Acta Paediatrica Scandinavica Suppl. 217, 60-62.

Eriksson, J., Franssila-Kallunki, A., Ekstrand, A., Saloranta, C., Widén, E., Schalin, C. \& Groop, L. (1989). Early metabolic defects in persons at increased risk for non-insulin dependent diabetes mellitus. New England Journal of Medicine 321, 337-343.

Faggiotto, A. \& Ross, R. (1984). Studies of hypercholesterolemia in the non-human primate. II. Fatty streak conversion to fibrous plaque. Arteriosclerosis 4, 341-356. 
Faggiotto, A., Ross, R. \& Harker, L. (1984). Studies of hypercholesterolemia in the non-human primate. I. Changes that lead to fatty streak formation. Arteriosclerosis 4, 323-340.

Fentem, P. H. (1992). Exercise in prevention of disease. British Medical Bulletin 48, 630-650.

Flatt, J. P. (1987). Dietary fat, carbohydrate balance, and weight maintenance: effects of exercise. American Journal of Clinical Nutrition 45, 296-306.

Fomon, S. J., Haschke, F., Ziegler, E. E. \& Nelson, S. E. (1982). Body composition of reference children from birth to age 10 years. American Journal of Clinical Nutrition 35, 1169-1175.

Frank, G. C., Berenson, G. S. \& Webber, L. S. (1978). Dietary studies and the relationship of diet to cardiovascular disease risk factor variables in 10-year-old children: the Bogalusa Heart Study. American Journal of Clinical Nutrition 31, 328-340.

Fraser, G. E., Phillips, R. L. \& Harris, R. (1983). Physical fitness and blood pressure in school children. Circulation 67, 405-411.

Freedman, D. S., Srinivasan, S. R., Burke, G. L., Shear, C. L., Smoak, C. G., Harsha, D. W., Webber, L. S. \& Berenson, G. S. (1987). Relation of body fat distribution to hyperinsulinemia in children and adolescents: the Bogalusa Heart Study. American Journal of Clinical Nutrition 46, 403-410.

Frohlich, E. D., Messerli, F. H., Reisin, E. \& Dunn, F. G. (1983). The problems of obesity and hypertension. Hypertension 5 Suppl., III71-III78.

Garvey, W. T., Olefsky, J. M. \& Marshall, S. (1986). Insulin induces progressive insulin resistance in cultured rat adipocytes: sequential effects at receptor and multiple post receptor sites. Diabetes 35, 258-267.

Geleijnse, J. M., Grobbee, D. E. \& Hofman, A. (1990). Sodium and potassium intake and blood pressure change in childhood. British Medical Journal 300, 899-902.

Goldstein, J. L., Ho, Y. K., Basu, S. K. \& Brown, M. S. (1979). Binding site on macrophages that mediates uptake and degradation of acetylated low density lipoprotein, producing massive cholesterol deposition. Proceedings of the National Academy of Sciences, USA 76, 333-337.

Gordon, T. (1970). The Framingham Diet Study: diet and the regulation of serum cholesterol. In The Framingham Study: an Epidemiological Investigation of Cardiovascular Disease, Section 24 [W. B. Kannel and T. Gordon, editors]. Washington, DC: Government Printing Office.

Grobbee, D. E., van Hooft, I. M. S. \& de Man, S. A. (1990). Determinants of blood pressure in the first decades of life. Journal of Cardiovascular Pharmacology 16, Suppl. 7, S71-\$74.

Guyton, A. C. (1989). Dominant role of the kidneys and accessory role of whole-body autoregulation in the pathogenesis of hypertension. American Journal of Hypertension 2, 575-585.

Hagberg, J. M., Ehsani, A. S., Goldring, D., Hernandez, A., Sinacore, D. R. \& Holloszy, J. O. (1984), Effect of weight training on blood pressure and hemodynamics in hypertensive adolescents. Journal of Pediatrics 104, $147-151$

Havlik, R. J., Hubert, H. B., Fabsitz, R. R. \& Feinlieb, M. (1983). Weight and hypertension. Annals of Internal Medicine 98, 855-859.

Hegsted, D. M., McGandy, R. B., Myers, M. L. \& Stare, F. J. (1965). Quantitative effects of dietary fat on serum cholesterol in man. American Journal of Clinical Nutrition 17, 281-295.

Henriksen, T., Mahoney, E. M. \& Steinberg, D. (1981). Enhanced macrophage degradation of low density lipoprotein previously incubated with cultured endothelial cells: recognition by receptors for acetylated low density lipoproteins. Proceedings of the National Academy of Sciences, USA 78, 6499-6503.

Hessler, J. R., Robertson, A. L. \& Chisholm, G. M. (1979). LDL induced cytotoxicity and its inhibition by HDL in human vascular smooth muscle and endothelial cells in culture. Atherosclerosis 32, 213-229.

Hofman, A., Walter, H. J., Connelly, P. A. \& Vaughan, R. D. (1987). Blood pressure and physical fitness in children. Hypertension 9, 188-191.

Hubert, H. B. (1984). The nature of the relationship between obesity and cardiovascular disease. International Journal of Cardiology 6, 268-274.

Inadera, H., Ito, S., Ishikana, Y., Shinomiya, M., Shirai, K., Saito, Y. \& Yoshịda, S. (1993). Visceral fat deposition is seen in patients with insulinoma. Diabetologia 36, 91-92.

Ingjer, F. \& Brodal, P. (1978). Capillary supply of skeletal muscle fibers in untrained and endurance-trained women. European Journal of Applied Physiology 38, 291-299.

Ingle, D. J. (1949). A simple means of producing obesity in the rat. Proceedings of the Society for Experimental Biology and Medicine 72, 604-605.

Jarrett, R. J. (1988). Is insulin atherogenic? Diabetologia 31, 71-75.

Jarrett, R. J. (1992). In defence of insulin: a critique of syndrome X. Lancet 340, 469-471.

Jennings, G., Nelson, L., Nestel, P., Esler, M., Korner, P., Burton, D. \& Bazelmans, J. (1986). The effects of changes in physical activity on major cardiovascular risk factors, hemodynamics, sympathetic function, and glucose utilization in man: a controlled study of four levels of activity. Circulation 73, $30-40$.

Julius, S., Gudbrandsson, T., Jamerson, K., Shahab, S. T. \& Andersson, O. (1991). The hemodynamic link between insulin resistance and hypertension. Journal of Hypertension 9, 983.986.

Kahn, H. A., Medalie, J. H., Neufeld, H. N., Riss, E., Balogh, M. \& Groen, J. J. (1969). Serum cholesterol: its distribution and association with dietary and other variables in a survey of 10,000 men. Israel Journal of Medical Sciences 5, 1117-1127.

Kannel, W. B. \& Thomas, H. E. (1982). Sudden coronary death: The Framingham Study. Annals of the New York Academy of Sciences 382, 3-20. 
Kaplan, N. M. (1989). The deadly quartet: upper-body obesity, glucose intolerance, hypertriglyceridemia, and hypertension. Archives of Internal Medicine 149, 1514-1520.

Kempner, W. (1948). Treatment of hypertensive vascular disease with rice diet. American Journal of Medicine 4, 545-577.

Keys, A., Anderson, J. T. \& Grande, F. (1957). Prediction of serum-cholesterol responses of man to changes in fats in the diet. Lancet ii, $959-966$.

Kiens, B. \& Lithell, H. (1989). Lipoprotein metabolism influenced by training-induced changes in human skeletal muscle. Journal of Clinical Investigation 83, 558-564.

Kinsell, L. W., Partridge, J., Boling, L., Margen, S. \& Michaels, G. (1952). Dietary modification of serum cholesterol and phospholipide levels. Journal of Clinical Endocrinology and Metabolism 12, 909-913.

Kohner, E. M. (1993). Diabetic retinopathy. British Medical Journal 307, 1195-1199.

Korner, P. I. (1994). Some thoughts on pathogenesis, therapy and prevention of hypertension. Blood Pressure 3, 7-17.

Kramsch, D. M., Aspen, A. J., Abramowitz, B. M., Kreimendahl, T. \& Hood, W. B. (1981). Reduction of coronary atherosclerosis by moderate conditioning exercise in monkeys on an atherogenic diet. New England Journal of Medicine 305, 1483-1489.

Krotkiewski, M., Mandroukas, K., Sjöström, L., Sullivan, L., Wetterqvist, H. \& Björntorp, P. (1979). Effects of long-term physical training on body fat, metabolism, and blood pressure in obesity. Metabolism 28, $650-658$.

Lapidus, L., Bengtsson, C., Larsson, B., Pennert, K., Rybo, E. \& Sjöström, L. (1984). Distribution of adipose tissue and risk of cardiovascular disease and death: a 12 year follow up of participants in the population study of women in Gothenburg, Sweden. British Medical Journal 289, 1257-1261.

Law, M. R., Frost, C. D. \& Wald, N. J. (1991). By how much does dietary salt reduction lower blood pressure? I. Analysis of observational data among populations. British Medical Journal 302, 811-815.

Lorenzi, M. (1992). Glucose toxicity in the vascular complications of diabetes: the cellular perspective. Diabetes \& Metabolism Review 8, 85-103.

McNamara, D. J., Kolb, R., Parker, T. S., Batwin, H., Samuel, P., Brown, C. D. \& Ahrens, E. H. (1987). Heterogeneity of cholesterol homeostasis in man: responses to changes in dietary fat quality and cholesterol quantity. Journal of Clinical Investigation 79, 1729-1739.

Martin, M. J., Hulley, S. B., Browner, W. S., Kuller, L. H. \& Wentworth, D. (1986). Serum cholesterol, blood pressure, and mortality: implications from a cohort of 361662 men. Lancet ii, 933-936.

Mayer, J. (1953). Glucostatic mechanism of regulation of food intake. New England Journal of Medicine 249, $13-16$.

Mayer, J., Marsha1l, N. B., Vitale, J. J., Christensen, J. H., Mashayekhi, M. B. \& Stare, F. J. (1954). Exercise, food intake and body weight in normal rats and genetically obese adult mice. American Journal of Physiology 177, $544-548$.

Mayer, J., Roy, P. \& Mitra, K. P. (1956). Relation between calorie intake, body weight, and physical work: studies in an industrial male population in West Bengal. American Journal of Clinical Nutrition 4, 169-175.

Messerli, F. H. (1982). Cardiovascular effects of obesity and hypertension. Lancet i, 1165-1168.

Miller, J. H. \& Bogdonoff, M. D. (1954). Antidiuresis associated with administration of insulin. Journal of Applied Physiology 6, 509-512.

Miller, J. Z., Weinberger, M. H., Daugherty, S. A., Fineberg, N. S., Christian, J. C. \& Grim, C. E. (1987). Heterogeneity of blood pressure response to dietary sodium restriction in normotensive adults. Journal of Chronic Diseases 40, 245-250.

Modan, M., Halkin, H., Fuchs, Z., Lusky, A., Chetrit, A., Segal, P., Eshkol, A., Almog, S. \& Shefi, M. (1987). Hyperinsulinemia: a link between glucose intolerance, obesity, hypertension, dyslipoproteinemia, elevated serum uric acid and internal cation imbalance. Diabète et Métabolisme 13, 375-380.

Moller, D. E. \& Flier, J. S. (1991). Insulin resistance-mechanisms, syndromes, and implications. New England Journal of Medicine 325, 938 948.

Morris, J. N., Marr, J. W., Heady, J. A., Mills, G. L. \& Pilkington, T. R. E. (1963). Diet and plasma cholesterol in 99 bank men. British Medical Journal i, 571-576.

Newman, W. P., Freedman, D. S., Voors, A. W., Gard, P. D., Srinivasan, S. R., Cresanta, J. L., Williamson, G. D., Webber, L. S. \& Berenson, G. S. (1986). Relation of serum lipoprotein levels and systolic blood pressure to early atherosclerosis: the Bogalusa Heart Study. New England Journal of Medicine 314, 138-144.

Nichols, A. B., Ravenscroft, C., Lamphlear, D. E. \& Ostrander, L. D. (1976). Independence of serum lipid levels and dietary habits: the Tecumseh Study. Journal of the American Medical Association 236, 1948-1953.

Ornish, D., Brown, S. E., Scherwitz, L. W., Billings, J. H., Armstrong, W. T., Ports, T. A., McLanahan, S. M., Kirkeeide, R. L., Brand, R. J. \& Gould, K. L. (1990). Can lifestyle changes reverse coronary heart disease? Lancet 336, 129-133.

Paffenbarger, R. S., Hyde, R. T., Wing, A. L., Lee, I.-M., Jung, D. L. \& Kampert, J. B. (1993). The association of changes in physical-activity level and other lifestyle characteristics with mortality among men. New England Journal of Medicine 328, 538-545.

Pilbeam, D. (1984). The descent of hominoids and hominids. Scientific American 250 (3), 60-69.

Quinn, D., Shiraj, K. \& Jackson, R. L. (1982). Lipoprotein lipase: mechanism of action and role in lipoprotein metabolism. Progress in Lipid Research 22, 35-78. 
Ramsay, L. E., Yeo, W. W. \& Jackson, P. R. (1991). Dietary reduction of serum cholesterol concentration: time to think again. British Medical Journal 303, 953-957.

Randle, P. J., Garland, P. B., Hales, C. N. \& Newsholme, E. A. (1963). The glucose fatty-acid cycle: its role in insulin sensitivity and the metabolic disturbances of diabetes mellitus. Lancet i, 785-789.

Rauramaa, R., Salonen, J. T., Kukkonen-Harjula, K., Seppänen, K., Seppälä, E., Vapaatalo, H. \& Huttunen, J. K. (1984). Effects of mild physical exercise on serum lipoproteins and metabolites of arachidonic acid: a controlled randomised trial in middle aged men. British Medical Journal 288, 603-606.

Ravussin, E., Lillioja, S., Knowler, W. C., Christin, L., Freymond, D., Abbott, W. G. H., Boyce, V., Howard, B. V. \& Bogardus, C. (1988). Reduced rate of energy expenditure as a risk factor for body-weight gain. New England Journal of Medicine 318, 467-472.

Reaven, G. M. (1988). Role of insulin resistance in human disease. Diabetes 37, 1595-1607.

Reichl, D., Myant, N. B., Brown, M. S. \& Goldstein, J. L. (1978). Biologically active low density lipoprotein in human peripheral lymph. Journal of Clinical Investigation 61, 64-71.

Richter, E. A., Hansen, S. A. \& Hansen, B. F. (1988a). Mechanisms limiting glycogen storage in muscle during prolonged insulin stimulation. American Journal of Physiology 255, E621-E628.

Richter, E. A., Hansen, B. F. \& Hansen, S. A. (1988 $b$ ). Glucose-induced insulin resistance of skeletal muscle glucose transport and uptake. Biochemical Journal 252, 733-737.

Roberts, S. B., Savage, J., Coward, W. A., Chew, B. \& Lucas, A. (1988). Energy expenditure and intake in infants born to lean and overweight mothers. New England Journal of Medicine 318, 461-466.

Romijn, J. A., Klein, S., Coyle, E. F., Sidossis, L. S. \& Wolfe, R. R. (1993). Strenuous endurance training increases lipolysis and triglyceride-fatty acid cycling at rest. Journal of Applied Physiology 75, $108-113$.

Rose, G. (1981). Strategy of prevention: lessons from cardiovascular disease. British Medical Journal 282, $1847-1851$.

Rosenthal, M., Haskell, W. L., Solomon, R., Widstrom, A. \& Reaven, G. M. (1983). Demonstration of a relationship between level of physical training and insulin stimulated glucose utilization in normal humans. Diabetes 32, 408-411.

Ross, R. (1986). The pathogenesis of atherosclerosis - an update. New England Journal of Medicine 314, 488-500.

Ross, R. \& Glomset, J. A. (1976). The pathogenesis of atherosclerosis. New England Journal of Medicine 295, $369-377,420-425$.

Schwartz, S. M. \& Benditt, E. P. (1977). Aortic endothelial cell replication. I. Effects of age and hypertension in the rat. Circulation Research 41, 248-255.

Shulman, G. I., Rothman, D. L., Jue, T., Stein, P., DeFronzo, R. A. \& Shulman, R. G. (1990). Quantitation of muscle glycogen synthesis in normal subjects and subjects with non-insulin-dependent diabetes by ${ }^{13} \mathrm{C}$ nuclear magnetic resonance spectroscopy. New England Journal of Medicine 322, 223-228.

Slater, E. (1991). Insulin resistance and hypertension. Hypertension 18 (3), Suppl., $108-114$.

Soman, V. R., Koivisto, V. A., Deibert, D., Felig, P. \& DeFronzo, R. A. (1979). Increased insulin sensitivity and insulin binding to monocytes after physical training. New England Journal of Medicine 301, $1200-1204$.

Somers, V. K., Conway, J., Johnston, J. \& Sleight, P. (1991). Effects of endurance training on baroreflex sensitivity and blood pressure in borderline hypertension. Lancet 337, 1363-1368.

Sørensen, T. I. A., Price, R. A., Stunkard, A. J. \& Schulsinger, F. (1989). Genetics of obesity in adult adoptees and their biological siblings. British Medical Journal 298, 87-90.

Sporik, R., Johnstone, J. H. \& Cogswell, J. J. (1991). Longitudinal study of cholesterol values in 68 children from birth to 11 years of age. Archives of Disease in Childhood 66, 134-137.

Staessen, J., Bulpitt, C. J., Thijs, L., Fagard, R., Joossens, J. V., Van Hoof, R. \& Amery, A. (1991). Pulse rate and sodium intake interact to determine blood pressure. American Journal of Hypertension 4, $107-112$.

Stamler, R., Stamler, J., Riedlinger, W. F., Algera, G. \& Roberts, R. H. (1978). Weight and blood pressure: findings in hypertension screening of 1 million Americans. Journal of the American Medical Association 240, $1607-1610$.

Steinberg, D. (1983). Lipoproteins and atherosclerosis : a look back and a look ahead. Arteriosclerosis 3, $283-301$.

Stout, R. W. (1968). Insulin-stimulated lipogenesis in arterial tissue in relation to diabetes and atheroma. Lancet ii, $702-703$.

Stout, R. W. (1991). Insulin as a mitogenic factor: role in the pathogenesis of cardiovascular disease. American Journal of Medicine 90, Suppl. 2A, 62S-65S.

Stout, R. W. \& Vallance-Owen, J. (1969). Insulin and atheroma. Lancet i, 1078-1080.

Strong, J. P. \& McGill, H. C. (1969). The pediatric aspects of atherosclerosis. Journal of Atherosclerosis Research 9, 251-265.

Stunkard, A. J., Foch, T. T. \& Hrubec, Z. (1986). A twin study of human obesity. Journal of the American Medical Association 256, 51-54.

Sundram, K., Hayes, K. C. \& Siru, O. H. (1994). Dietary palmitic acid results in lower serum cholesterol than does a lauric-myristic acid combination in normolipemic humans. American Journal of Clinical Nutrition 59, $841-846$.

Task Force on Blood Pressure Control in Children. (1987). Report of the second task force on blood pressure control in children - 1987. Pediatrics 79, 1-25.

Texon, M. (1980). Hemodynamic Basis of Atherosclerosis. New York, Hemisphere. 
Texon, M. (1986). The hemodynamic basis of atherosclerosis. Further observations: the linear lesion. Bulletin of the New York Academy of Medicine 62, 875-880.

Tran, Z. V. \& Weltman, A. (1985). Differential effects of exercise on serum lipids and lipoprotein levels seen with changes in body weight - a meta analysis. Journal of the American Medical Association 254, 919-924.

Van Hooft, I. M. S., Hofman, A., Grobbee, D. E. \& Valkenburg, H. A. (1988). Change in blood pressure in offspring of parents with high or low blood pressure: the Dutch hypertension and offspring study. Journal of Hypertension 6, Suppl. 4, S594-S596.

Virchow, R. (1858). Die Cellularpathologie in ihrer Begründung auf physiologische und pathologische Gewebelehre. Berlin: Hirschwald.

Voors, A. W., Webber, L. S. \& Berenson, G. S. (1979). Time course studies of blood pressure in children - the Bogalusa heart study. American Journal of Epidemiology 109, 320-334.

Webber, L. S., Voors, A. W., Srinivasan, S. R., Frerichs, R. R. \& Berenson, G. S. (1979). Occurrence in children of multiple risk factors for coronary artery disease: the Bogalusa Heart Study. Preventive Medicine 8, $407-418$.

Weintraub, M. S., Rosen, Y., Otto, R., Eisenberg, S. \& Breslow, J. L. (1989). Physical exercise conditioning in the absence of weight loss reduces fasting and postprandial triglyceride-rich lipoprotein levels. Circulation 79 , $1007-1014$

Wong, N. D., Hei, T. K., Qaqundah, P. Y., Davidson, D. M., Bassin, S. L. \& Gold, K. V. (1992). Television viewing and pediatric hypercholesterolemia. Pediatrics $90,75-79$.

Wood, P. D., Haskell, W. L., Blair, S. N., Williams, P. T., Krauss, R. M., Lindgren, F. T., Albers, J. J., Ho, P. H. \& Farquhar, J. W. (1983). Increased exercise level and plasma lipoprotein concentrations: a one-year, randomized, controlled study in sedentary, middle-aged men. Metabolism 32, 31-39.

Wood, P. D., Stefanick, M. L., Dreon, D. M., Frey-Hewitt, B., Garay, S. C., Williams, P. T., Superko, H. R., Fortmann, S. P., Albers, J. J., Vranizan, K. M., Ellsworth, N. M., Terry, R. B. \& Haskell, W. L. (1988). Changes in plasma lipids and lipoproteins in overweight men during weight loss through dieting as compared with exercise. New England Journal of Medicine 319, 1173-1179.

World Health Organization (1985a). Blood Pressure Studies in Children. Technical Report Series No. 715. Geneva: WHO.

World Health Organization (1985b). Sudden Cardiac Death. Technical Report Series No. 726. Geneva: WHO.

Young, A. A., Bogardus, C., Wolfe-Lopez, D. \& Mott, D. M. (1988). Muscle glycogen synthesis and disposition of infused glucose in humans with reduced rates of insulin-mediated carbohydrate storage. Diabetes 37 , 303-308. 